\title{
Investigating the Strategies Used to Translate English Advertisement Slogans into Arabic
}

\begin{abstract}
:
This paper deals with a text-specific translation. It covers the translation of a non-literary text which falls under the subject field of marketing. It aims at investigating the translation strategies used in the translation of advertisements as a recent orientation in the field of translation, which is advertisements' translation. The paper is composed of a theoretical aspect and a practical one. The theoretical aspect, introduces an overview of translation (translation studies) notably; specialised translation, the translation of a text-specific nature in the field of advertising is, then, introduced and defined, as well as the translation strategies and techniques used for rendering this type of items. In the practical aspect, the translation strategies used to render English advertisement slogans into Arabic are investigated by means of a corpus of English slogans (comparable component) with their Arabic counterparts (parallel component). Their analysis is conducted to provide information about thequantity (frequency of the translation methods used in this context) and quality of these translating methods.

Key words: translation, non-literary text, advertisements' translation, strategies, advertisement slogans.
\end{abstract}

\author{
AYADI Amina \\ Faculty of Letters and Languages \\ Department of Foreign Languages \\ University of Mentouri \\ Constantine
}

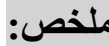

تبحث هذه الدراسة في موضوع من مواضيع الترجمة المتخصصة حيث تشمل إحدى مجالات الترجمة اللادبية رونة

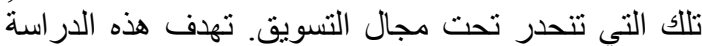
إلى البحث عن استراتجيات الترجمة المتبعة في نقل توجه

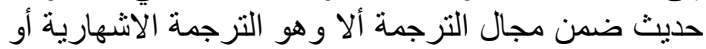

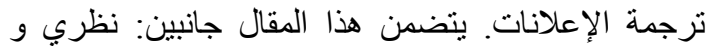

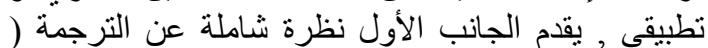

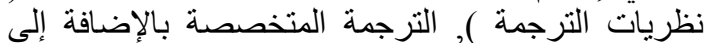

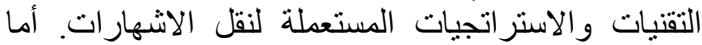

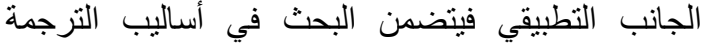

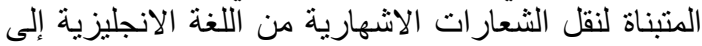

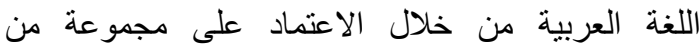

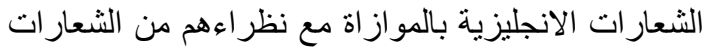

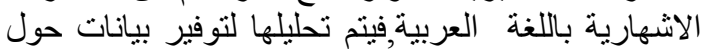

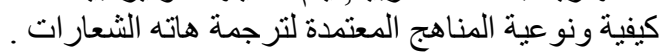

\section{Introduction :}

The emergence of the LSP (language for specific purposes) approach has led to the consideration of the translation of LSP as an explicit sub-branch of translation studies. Among these specific languages to be translated is the language of marketing and advertising. Due to globalization and the opening of international markets on each other, translation has become an urgent necessity despite the dominance of the English language. 
This has set the ground for new insights for investigations in the translation field. This article investigates the translation strategies used by Arab translators to render English advertisement slogans into Arabic. The study aims at providing a more practical purpose about this type of translation because there is a gap in the literature, particularly the Arabic literature regarding the translation of advertisements into Arabic. In addition to that, this work aims at providing hints and guidelines for translation students or future translators, who must be aware of the translation of different linguistic pieces, no matter their nature or their field of existence. The experimental aspect is approached by means of a corpus analysis.

\section{The Theoretical Aspect}

\subsection{An Overview of Translation Studies}

Translation has been as old as human communications; both the spoken and the written forms of translation have played a pivotal role in decoding texts for religious and knowledgeable purposes. However, translation has not been an independent academic field until the 1970s, known then as 'translation studies', which has been introduced for the very first time by Holmes who has seen it important to study translation as an academic subject. Until 1988, Holmes prepared a written paper about this field which was still in its embryonic stages. Translation studies has stepped forward as a discipline related to translation in its different and possible forms. It is also concerned with the problems encountered in translation and when translating (2000: 173). Holmes states: "Nevertheless, the designation 'translation studies' would seem to be the most appropriate of all those available in English, and its adoption as the standard term for the discipline as awhole would remove a fair amount of confusion and misunderstanding" (2000: 173). 'Translation theory' is another term also used by Holmes to refer to 'theoretical translation studies', the aim of which is "to develop a full, inclusive theory accommodating so many elements that it can serve to explain and predict all phenomena falling within the terrain of translating and translation, to the exclusion of allphenomena falling outside it" (2009: 9-10). 'Translation studies' has gradually been a powerful approach approved by many scholars such as Snell-Hornby (1988) and Baker (1997)...etc. Translation studies was more interested in the literary translation, yet this is no more the case, more focus has been allocated to non-literary translation ,too. Thus, translation studies becomes a new independent approach which has come out to discuss different possible problems and issues related to translation in its different kinds, as affirmed by Holmes who states that this discipline deals with: "the complex of problems clustered round the phenomenon of translating and translators" (2009: 9-10).

\subsection{Specialised Translation/Non-literary Translation}

LSP, language for specific purposes is an approach which has been most related to the English language. Thus, ESP has emerged (English for specific 
purposes) to target second language learners and provide them with a variety of languages which may be used by particular members of any subject field (medicine, politics, economy...), in order to raise their communicative competence. Hence, the translation of LSP has been considered as a sub-field of translation studies. According to some translators, the translation of LSP or specialised translation refers to the translation process and it is the same as professional translation. Others believe that specialised translation refers to the translation of any text which bears a specific subject (distinct from general translation). On the other hand, the translation of texts which address specialists is the only translation which should be considered specialised, according to some theorists. "As compared to translations considered generally [...], specialised translations suppose knowledge and command of the specialized notions and terms specific to the field to which they belong. Specialized languages give the name of specialized translations", this indicates another belief; the translation of specialists for non-specialists is the specialised translation (Armasar: 251). According to Fiola:

"Translation is specialized when it deals with content and format bearing characteristics that can be attributed to an area of specialized knowledge. These characteristics may be lexical or syntactical in nature. For example, a text referring to a medical procedure, whether aimed at specialists or at the general population, is specialized due to its terminological content, and its translation is therefore specialized" (2013: 59).

All the three fore definitions are applicable to the advertising field, therefore no matter how the specialieed translation is; the translation of advertisements is one example. The translation of advertisements falls under the non-literary translation, 'specialised', 'pragmatic' or 'non-fictitious' text, whatever its name. Gibová states: "The label "non-literary text", as broad as it may seem, covers a wide range of texts from administrative, legal and other official documents, via economic and business texts, scientific, technical up to publicist texts" (2012: 18).

\subsubsection{Advertising and Translation}

Advertising plays a critical role in the success of a company in this increasingly commercialised society. In the age of globalisation, effective translations can be crucial when businesses are targeting a foreign market. However, achieving an effective translation of advertisements has long been a hard nut to crack for translators. Academically, this area of Translation Studies has also been challenging for researchers (Munday: 2004).Advertising texts are special; they use words to communicate, evoke, suggest, provoke... In short, they use words to sell. That is why advertising translation must both convey the original message and awaken the same sensations, 
perceptions and reactions as the original text. As far as advertisement translation is concerned, it is not enough to translate word for word; advertising translators must take into account cultural references and word play (word choice), and adapt the message to be conveyed to the target audience. For Anholt advertisement translation resembles painting the top of an iceberg, he states:

"Translating advertising copy is like painting the tip of an iceberg and hoping the whole thing will turn red.What makes copy work is not the words themselves, but subtle combinations of thosewords, and most of all the echoes and repercussions of those words within the mind of the reader [...] Advertising is not made of words, but made of culture" (2000: 5).

The statement emphasizes on the difficulty of translating advertisements in the sense that their translation poses a demanding challenge for translators. As well as linguistically perfect translations, cultural background is also of great significance. An advertising message must be adapted to the relevant culture in order to achieve the desired effect there, De Mooij regards:

"As in any communication process, both the advertising message and the schemata of theconsumer are influenced by their culture, and it is difficult to transfer advertising to other cultures without understanding how culture operates" (2004: 181).

\subsubsection{Advertising and Culture}

Advertisements are said to be cultural mirrors as they reflect society values, norms or habits. Leiss and jhally defined advertising as: "advertising is not just business expenditure undertaken in the hope of moving merchandise off the store shelves, but is rather an integral part of modern culture" (1986: 7). This indicates that advertisements have become a modern cultural aspect since they have been introduced to every human's social sides: art, sport, food ...etc. According to Bullmore, an effective advertisement is the one which represents the culture in question since advertisements carry information about the products as well as some cultural aspects. In other words, Bullmore believes that advertising is more than providing information about the product, but it transmits some aspects of a particular community's culture and this is the key for effective advertisements; people respond better to advertisements which reflect their culture (in de Mooij: 33). Much of debate has been raised since the article of Theodore Levitt has come out in 1983 which was in favour of the standardisation of advertisements and markets. Levitt believes, that because of globalisation, development, tourism, transport, and communication, the world has become more homogenous. Tastes and needs are pretty much common; this creates the idea of the global consumer and the exclusion of cultural aspects in advertisements. He adds that in the coming years, companies will use only standardised advertising without taking into consideration the cultural nuances 


\section{Investigating the Strategies Used to Translate English Advertisement Slogans into Arabic}

(1983: 2). In contrast to this view, De Mooij argues that a close relation lies between culture and advertising; advertising must be culturally adapted to meet consumers' needs. She has well portrayed this relation in her saying: "consumers are products of their culture" which determines that cultural or social context influences consumers' perceptions of advertisements. De Mooij considers cultural diversity to be an obstacle for standardised advertisements, because people from different cultural backgrounds may interpret the same advertisements differently. She states: "If the advertising message does not fit the consumers' schema, they will ignore the message, and the ad is consequently wasted" (2004: 181).

Shimp confirms: "the same sign can mean different things to different people at different times and in different contexts" (1997: 119). Thus a standardised advertisement for global markets is a relative matter as long as cultural diversities exist. De Mooij affirms: "we all have universal needs, but the way we satisfy them differs among cultures" (2005: 37).

\subsubsection{Translation of Advertisements: Which Translation Strategies to Use?}

To expand their sales overseas and go international, companies must adopt successful translations. When an advertisement is being translated, there are certain elements involved and certain skills needed by translators in order to transmit the impact an advertisement has on the domestic market in the foreign market. As for the translation of advertisements as a non-literary text, Popovič believes that it is a "stylistic operation which is based not on the transfer of aesthetic but pragmatic information" (1977: 192). This implies that the translation of such texts is about the translation of effect rather than the form. Thus, the meaning and the effect are prior than the form and aesthetic. Popovic refers to this translation as a stylistic operation which indicates that this translation requires stylistic touch from the translator's part even if the aesthetic transfer is not required and of a less significance. This leads us to talk about creativity in advertisement translation, which is a very required factor to provide successful versions for difficult source texts. Therefore, Transcreation was created based on the importance of creativity in successful advertisement translation. Valdés Rodriguez explains that the complex nature of advertisements makes of creativity an essential quality which must be shown by translators in this field, in order to achieve an acceptable target version. She quotes:

"Advertisements are a dynamic synthesis of diverse components: on the one hand, there is a visual part, which may be static, such as graphic language or printed pictures, or dynamic, as television moving images; on the other hand, there is an oral component, which may be represented by the paralinguistic oral features, by the text read, dubbed or sung, or by music, noise or silence in audiovisual advertisements. These different codes do not 
signify separately but contribute to the global meaning of the advertisement (...). These elements need to be creatively combined to draw the receivers' attention and arouse their interest in the product and likewise creatively brought together in the target text to trigger the same or similar effect" (2008: 38).

Advertisements translation can be split into the translation of three elements: the translation of the brand name, the translation of the body and that of the catchy phrase (slogans). First, related to the translation of the brand name, it has been noticed that they are generally kept in their original language, most often in English, due to a "Western need for consistency" (De Mooij: 2004), in addition to the fact that some band names cannot be rendered otherwise they will sound weird and meaningless. Second, Wells et al. define the body copy as "the text of the ad [vertisement]" (2000: 326). The body copy seems to be the easiest part to render especially when it does not include technical terms, Arens et al. focuses on the three coming factors to make a good copy: simplicity, credibility, and clarity (2009: 366). Obviously, literal translation would be a successful translation strategy to render a simple credible clear body copy. However, some technical words can be used and made its translation a bit tougher. Abu-shehab carried out a study to analyze English advertisement body copies translated into Arabic. The most adopted translating strategies found were respectively as follows: literal translation, substitution, couplets (partial translation) when the technical terms are provided with parenthetical expressions, i.e. some explanations are provided between parenthesis whereas, transliteration and full substitution are adopted when the technical terms are not explained (2011: 64-71). Third, the catchy phrase or the slogans, is a major challenge in the translation of advertisements. Dan refers this, to the fact that advertisement slogans "often play on the double meaning of words, making the message difficult to understand. The use of ambiguity and connotative meanings of words can lead to multiple interpretations of the slogans" (2015: 13). In addition to that, the English advertisement brand names and even slogans are sometimes made by taking into account the verbal system and the phonological presentation (rhymes, explicit repetition of words) so that they would be easier for pre-supposed customers to recall (e.g. if anyone can, CANON can). This makes the translation task harder because of equivalence problems, De Mooij adds: "literal translation is often not a good solution, precisely because of the interdependence of language and culture" (2004: 188).

2. Investigation of the Translation Strategies Used to Render English Advertisement Slogans into Arabic

\subsection{Methodology}

The framework of analysis in this study involves an analysis of a data corpus collected over the four past years. The analysis consists of English advertisement slogans along with Arabic counterparts. It entails a comparative 


\section{Investigating the Strategies Used to Translate English Advertisement Slogans into Arabic}

study in terms of syntax, semantics and pragmatics in order to deduce the strategies applied by translators to render these formations.

\subsection{The Corpus}

The corpus in question includes 62 slogans, out of which, only six have been picked up for analysis in this paper due to space constraints. The slogans have been gathered from English and Arabic television screens and from magazines as well. The Arabic versions are in classical Arabic for they are made to address different Arabs from different Arab countries. The aim behind this comparative analysis is to deduce the strategies the Arabic translators resorted to when rendering these slogans, in addition to find out which strategy is mostly used to render them successfully.

\subsection{A Qualitative and a Quantitive Analysis of the Corpus \\ 1. "Connecting people"}

The phrase aboveis a noun phrase used as an advertising slogan for Nokia Company. This short phrase carries a complete meaning in the advertising context. It has been translated into Arabic as "لنتواصل"; the translator has modified the form of the message by a change in the semantics and in the syntactic pattern. The translator reduced the English slogan to one Arabic word equivalent only. As far as the translation strategy used to render this slogan into Arabic is concerned, the translator has hired equivalence when he describes the same situation but in a different stylistic and structural mean. For the first look, it may appear that the translator has omitted what is unnecessary (people) and has preserved what is essential (the connection). In fact, the part which seems to be deleted is implicitly substituted by the translator's inclusion of himself as a member of the connection activity by using "ن" which refers to "we" as people. This has been proved to be a creative solution for such rendering. However, the Arabic slogan does not convey the same meaning as the English one. If the Arabic slogan were backtranslated into English, it would be "let's connect". Functionally, this is different from the original meaning. The translator has avoided word for word translation because employing this strategy will serve neither the linguistic (meaning) nor the commercial purposes (effect, attractiveness) of a slogan. The slogan could be rendered into: "لإلكي نتواصل" "or even shorter than that as , these versions are closer to the original slogan which implicitly indicates that Nokia instruments are made to connect people and keep them in touch and does not make a suggestion to connect. Hence, 'Nokia' slogan was translated freely (oblique translation) through the equivalence strategy.

\section{2. "Knowledge into action"}

Thisis a slogan used to invite people to donate to help carrying out researches and investigations on cancer and help patients with this disease. It has been translated into Arabic as "رحلة علم هدفها الحياة". The English slogan means, let us put the knowledge we got from the researches and investigations 
into practice. This implicitly states the idea of saving people's and patients' lives. The translator has kept the meaning of the original slogan and has even made his version sound more appealing and attractive by including الحياة" هدفها". This phrase makes of the Arabic slogan direct and inviting. Using the equivalence strategy, the slogan has been successfully translated, because a sort of a sameness relationship has been established between the source and the target slogan in addition to this, attractiveness and a strong appeal have been included in the Arabic version. So, the slogan was translated freely adopting the equivalence strategy and inserted the addition technique to get a clarified slogan. Clarity makes attractiveness and effectiveness of the slogan.

3. "We lead, others follow", is an English slogan of a car advertisement. It expresses a high level of confidence from the company's side and states clearly that their products are original ones made by leaders whereas the other products are just a counterfeit. The advertisement was presented on Arabic televisions; the slogan was rendered into Arabic as follows: ”. This translation is literally a literal translation. The translator rendered the slogan word for word using the calque technique. Thus, both of the content and the form are transferred. The same meaning of the source message has been transmitted into the target message in addition to the original grammatical structure and punctuation which have been preserved the same in the target version. The translation of the slogan as: "الأخرون يلاحقون , "نحن نقود is problematic, in my view, for two reasons. The translation strategy used to translate the slogan into Arabic is inappropriate for it results in a nonattractive version which makes it ineffective. Moreover, the slogan should display the advertised product qualities and focus on them rather than mentioning others and making a comparison as it is shown in the second part of the slogan "others follow". Such focus will convince the viewers instead of drawing their attention to think about other brands and make comparisons. In addition to this, the use of the Arabic verb "يلاحقون" was inappropriate. It could be translated as "يقتدون" for instance. This makes of the second part more formal and deferential. In fact, the Arabic slogan reflected the English slogan intended meaning; however, the translator should have thought not only of meaning or form but also of the effect. Despite the fact that the strategy used to render this example, conveys the exact source meaning and is linguistically correct, literal translation was inappropriate for it resulted in a non- attractive and may be an ineffective version. It is really hard to think of another possible version for the English slogan. This may take a considerable amount of time and effort to transmit it successfully. The slogan can possibly be adapted into: ”"إنتا القدوة" or.

4. "Incredible moments"

The English advertisement, where the slogan above appears, is tightly related to its visuals without which the slogan will not be clear. It presents a 


\section{Investigating the Strategies Used to Translate English Advertisement Slogans into Arabic}

picture of a mother showering her baby who is enjoying his bath and refers in the slogan to this as a good memorable pain and tear free moment for babies. The slogan was translated as "وراء كل ذكرى جميلة في حياة طقلك". The advertised product is the one which makes of a child's life full of incredible moments. Unlike the original slogan, the translated one has been made clearer and has not relied on the picture to deliver its message; though it has been made longer. In terms of translation, the slogan does not convey the same meaning of the original one besides being long. This may affect its attractiveness and elegance which may also affect its effectiveness and memorability. The translator could not render the English slogan into Arabic literally "لحظات لا تصدق"; it would be ambiguous and senseless. So, the Arabic slogan has been fully adapted by a total change of the slogan concept and the addition of new items that have not existed before to overcome the source slogan ambiguity and make it clearer. Moreover, the Arabic translator has employed substitution when he replaces "moments" by "memories". This substitution was unnecessary because both of the words act similarly; however, the second indicates that memories are moments at first and this means that this product will make your present (moments) and past (memories) nice and joyful. The slogan could be translated through the equivalence strategy as follows: "لحظات لا تنسى", Which is faithful, shorter and even appealing.

\section{5. "Life is easier"}

The slogan sounds incomplete however, taking a look at the whole advertisement visuals, verbal and non-verbal signs makes it clear and shows that without this particular product your life will not be easy but having it makes it easier. Slogans tend to be mysterious and incomplete and this is what makes them entities of a poetic nature. This slogan is simple, short and conveys a clear meaning. It was translated as "Moulinex الحياة أسهل مع", the slogan has been transmitted into Arabic literally. The translator has rendered "life" into "الحياة", the comparative "easier" into the comparative adjective "الحياة أسهل" what is noticed is adding the brand name into the Arabic slogan, the translator may assume that "الحياة أسهل" is an elliptical phrase which does not deliver a full meaning on its own, so some necessary words need to be added such as: "الحياة أسهل الأن“" Yet, the meaning may still incomplete unless it is supported by a picture to illustrate it. In fact, this is done to complete the slogan's meaning and make it clearer by using the brand name. The translation seems to be successful for it is faithful and it respects the advertisement slogans principles and render them into Arabic (shortness, elegance, attractiveness, meaningfulness). So this slogan was rendered literally, literal translation does not result in a meaningless version as it does not lessen the verbal strength of the slogan. 
6."Tough on germs, gentle on hands",

This slogan was rendered as: "قوي على الجراثيم , لطيف على الأيدي". The slogan was translated in a transparent way; the original meaning is clearly mirrored in the target version; backtranslation would also deliver the same intended meaning of the original slogan. The translator has translated the slogan word for word, the same meaning is kept, the structure and even the punctuation mark (,). The slogan is relatively long, but it is divided into two phrases which include two different contradictory ideas (paradoxes), this makes of the slogan faithful. Another slogan translation which proves that word for word translation may work in transmitting advertisement slogans without affecting their meaning and effectiveness negatively.

\section{Conclusion}

The translation of advertisement slogans is delicate and sensitive. The translator has to take into account the linguistic, cultural and commercial (effect) aspects of the slogan. Attractiveness or elegance of expression, faithfulness and briefness are aspects to be transmitted, too. The receiver and the aim of the translation task are the main factors which influence the function of the translation and which should be taken into account by the translator. As a result of our descriptive and comparative analysis of the sample slogans, the conclusions that may be drawn are as follows:

1) Contrary to what was raised in the hypothesis, literal translation was used to transmit English advertisement slogans into Arabic and it did not always result in an ineffective Arabic version as it did not weaken the verbal strength of the target slogan.

2) It has been shown that the cases where literal translation was not working can be referred to a linguistic incompetence rather than to the translation method or to the Arabic language inflexibility.

3) Free translation seems to be the most adopted and recommendable method to transmit English advertisement slogans into Arabic where keeping the sense or the content unchanged is primary.

4) Adaptation, equivalence, and modulation were the most sub-strategies, which belong to the free translation strategies, which have been employed by translators of English advertisement slogans when transmitting them into Arabic. This is done to meet the target audience linguistic properties, to achieve attractive effective messages and, in some cases, to overcome a linguistic incompetence

5) The change of a situation due to a cultural difference or adaptation was unfortunately not illustrated in the sample chosen, the slogans analysed were almost all culturally appropriate with no connotation reference. 


\section{Investigating the Strategies Used to Translate English Advertisement Slogans into Arabic}

6) Almost all the Arabic versions were functionally acceptable as they were meaningful, concise, and attractive.

7) The use of the standard Arabic in English translated advertisement slogans or commercials could be more successful and expressive if only creativity is highly hired in this translation. Thus, the Arabic language could be commercially used and accepted as well as the English and the French languages.

\section{Bibliography}

Abu-Shehab, Nahedah Hashim. Translating Brochures Advertising Personal Care Products from English into Arabic: Strategies and Linguistic Inaccuracy.An-Najah National University, Faculty of Graduate Studies, 2011: 64-71.

Anholt, Simon. Another One Bites the Grass. Making Sense of International Advertising, John Wiley \& Sons: New York, 2000: 5.

Arens et al. Contemporary Advertising. McGraw- Hill: Irwin, 2009: 366.

Armasar, Ioana-Paula. Apects of Specialized Translations in the Field of Economics. Bulletin of the Transilvania University of Braşov Series V: Economic Sciences. Vol. 7, 2014: 251.

Bullmore in de Mooij, M. Global Marketing and Advertising: Understanding Cultural Paradoxes. Thousand Oaks, CA: Sage, 1998: 33.

Dan, Lavinia (Nădrag).Techniques for the Translation of Advertising Slogans. Arhipelag XXI Press, Tîrgu Mureș, "Ovidius" University of Constanța, 2015: 13.

De Mooij, M. Translating Advertising, Painting the Tip of an Iceberg. The Translator. Volume 10, 2004: 181,188.

-----. Global Marketing and Advertising: Understanding Cultural Paradoxes. Thousand Oaks: SAGE Publications, Inc, 2005:37.

Fiola, M. Should the Market Dictate the Content of Specialized Translation Curricula? Connexions, international professional communication journal, Ryerson University, 2013: 59.

Gibová.k. Translation Procedures in the Non-literary and Literary Text Compared (based on an analysis of an EU institutional-legal text and novel excerpt "The Shack" by William P. Young). University of Presov Faculty of Arts Institute of British and American Studies, 2012: 18.

Holmes, James, S. "The Name and Nature of Translation Studies". The Translation Studies Reader. Ed. Lawrence Venuti, second ed. Routledge, 2000: 173.

Munday, J. The Routledge Companion to Translation Studies. Routledge: Oxon, 2009: 9-10.

Leiss, W.K.S. and Jhally. Social Communication in advertising: persons, products, and images of well being. Metheun: New York, 1986: 7. 
Levitt, T. The Globalization of Markets. Harvard Business School Reprint, 1983: 2.

Munday, J.Advertising: Some Challenges to Translation Theory. The

Translator

Volume 10, 2004: 199.

Popovič, A. The Nature of Translation. Essays on the Theory and Practice of literary Translation. The Hague: Mouton, 1977: 192.

Shimp, T. E. Advertising. Promotion and Supplemental Aspects of Integrated Marketing Communication, 4th Edition. The Dryden Press: Fort Worth, Texas, 1997:119.

Valdés Rodríguez, M. Cristina. Creativity in Advertising Translation. Universidad de Oviedo. Quaderns de Filologia, Estudis literaris, Vol. XIII ,2008: 38 .

Wells et al. Advertising: Principles and Practice. Prentice - Hall: New Jersey, 2000: 326. 